\title{
Copper concentration in multiple sclerosis: a systematic review and meta-analysis
}

\author{
Mohammad Sarmadi $^{\text {a,b }}$, Zeinab Bidel ${ }^{\text {c,d }}$, Fereshteh Najafi ${ }^{\text {b,e }}$, Rema Remakrishnan ${ }^{\text {c,d }}$, Farshad Teymoori ${ }^{\text {f,g }}$, \\ Hassan Azhdari Zarmehri ${ }^{\mathrm{b}, \mathrm{h}}$, Milad Nazarzadeh ${ }^{\mathrm{c}, \mathrm{d}, *}$ \\ a Department of Environmental Health Engineering, School of Health, Torbat Heydariyeh University of Medical Sciences, Torbat Heydariyeh, Iran \\ ${ }^{\mathrm{b}}$ Neuroscience Research Center, Torbat Heydariyeh University of Medical Sciences, Torbat Heydariyeh, Iran \\ ${ }^{\mathrm{c}}$ Deep Medicine, Oxford Martin School, University of Oxford, UK \\ d Nuffield Department of Women's and Reproductive Health, Medical Science Division, University of Oxford, UK \\ e Department of Public Health, School of Health, Torbat Heydariyeh University of Medical Sciences, Torbat Heydariyeh, Iran \\ ${ }^{\mathrm{f}}$ Nutrition and Endocrine Research Center, Research Institute for Endocrine Sciences, Shahid Beheshti University of Medical Sciences, Tehran, Iran \\ ${ }^{g}$ Department of Nutrition, School of Public Health, Iran University of Medical Sciences, Tehran, Iran \\ ${ }^{\mathrm{h}}$ Department of Physiology, School of Paramedical Sciences, Torbat Heydariyeh University of Medical Sciences, Torbat Heydariyeh, Iran
}

\section{A R T I C L E I N F O}

\section{Keyword}

Multiple sclerosis

Copper

Serum

Plasma

Cerebrospinal fluid

Meta-analysis

\begin{abstract}
A B S T R A C T
Background: A wide range of risk factors, from genetic to environmental, have been identified to play role in the etiology of multiple sclerosis. However, the role of trace element remains mostly unknown. We sought to combine all available evidence to assess the association between copper concentration and multiple sclerosis.

Methods: This systematic review and meta-analysis was conducted based on PRISMA guidelines. PubMed, Scopus, Embase, and Web of Science were searched since inception till July 2020. Observational studies that assessed copper as exposure in serum, plasma, whole blood, and cerebrospinal fluid were included. Standardized mean differences (SMD), comparing the mean of copper concentration in multiple sclerosis patients versus healthy controls, were considered as the measure of association. The fixed-effect model with inverse variance weighting was used to combine the findings.

Results: Twenty studies inclusive of 797 multiple sclerosis cases and 875 healthy controls. were included in the meta-analysis (all case-control studies). The combined SMDs were 1.25 (95\% confidence interval [CI] 0.95 to 1.55 , number of included studies $[\mathrm{n}]=4$ ) in plasma, 0.45 (CI 0.22 to $0.68, n=4$ ) in whole blood, 0.19 (CI 0.06 to $0.33, n=12$ ) in blood serum and 1.23 (CI 0.83 to $1.64, n=4$ ) in cerebrospinal fluid.

Conclusions: We found a higher concentration of copper in multiple sclerosis patients than healthy controls. The possible causal nature of the observed associations warrants further investigation with prospective data.
\end{abstract}

\section{Introduction}

Multiple sclerosis (MS) is a chronic autoimmune and inflammatory demyelinating disease of the central nervous system (CNS) (Morandi et al., 2017), with an estimated disability-adjusted life year of 15.6 per 100,000 general population (Hay et al., 2016). It is one of the most common reasons for neurological disability (Bredholt and Frederiksen, 2016), particularly in younger age groups and women (Houtchens et al., 2018; Toschi et al., 2019; Zuluaga et al., 2019). The high disability, together with the high costs associated with treatment and complications, impose an increasing burden on healthcare systems as well as the patients and their families (van den Hoogen et al., 2017).
A wide range of risk factors, from genetic to environmental, have been identified to play role in the etiology of MS (Olsson et al., 2016). Current environmental risk factors with a high level of evidence are viral infections (Ascherio et al., 2001), lack of sunlight and vitamin D (Ascherio et al., 2010), and smoking (Handel et al., 2011; Riise et al., 2003), but the role of other environmental risk factors such as trace elements remains mostly unknown. Copper, as a vital trace element, plays an essential role in the synthesis of myelin (Eliaeson et al., 2008), immune system, and CNS functions (De Riccardis et al., 2018; Sedighi et al., 2013a). However, there is a wealth of evidence that the accumulation of large amounts of copper in the blood and CNS can cause major health problems (Gupta and Lutsenko, 2009; Tapiero and Tew, 2003; Usman et al., 2013). There is some level of evidence that suggest MS patients have a higher

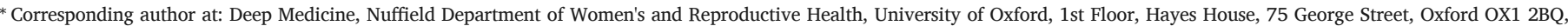
UK.

E-mail address: milad.nazarzadehlarzjan@wrh.ox.ac.uk (M. Nazarzadeh)
} 
level of copper concentration in comparison with healthy controls (Ghazavi et al., 2012; Rieder et al., 1983; Socha et al., 2017). In contrast, some other studies have been shown null or negative associations of copper concentration with MS (Palm and Hallmans, 1982; Ristori et al., 2011). Given this mixed evidence and small sample size of individual studies, we conducted a systematic review and meta-analysis to combine all available evidence to assess the association between copper concentration and MS disease.

\section{Methods}

\subsection{Search strategy}

We conducted a systematic review and meta-analysis based on PRISMA guidelines (Moher et al., 2009). The search was conducted for observational studies that measured copper in serum, plasma, whole blood, and cerebrospinal fluid. PubMed, Scopus, Embase, and Web of Science were searched since inception till July 2020 without any restriction. Furthermore, a complimentary search was carried out on leading MS or neurology journals. Besides, all reference lists of identified papers, reviews, meta-analyses, letters, and other relevant documents were searched manually. For the electronic search in databases, the following combinations of keywords relating to MS and copper were used: ('Copper' OR 'Trace Elements' OR 'Heavy Metal' OR 'Trace metal') AND ('Multiple Sclerosis' OR 'Optic Neuritis'). Two trained investigators (MS and FN) separately screened titles and abstracts for eligible studies. Also, the reference lists of the retrieved articles were scrutinized for additional relevant studies. If there was inadequate information in the paper, we contacted the corresponding authors via email. The same two investigators checked the full text of retrieved papers, and any disagreements were resolved by consensus or adjudication of the principal investigator.

\subsection{Study selection and exclusion}

The inclusion criteria were as follows: (1) all type of observational studies with a control group (including case-control, cohort, and cross-sectional studies); (2) studies with copper as measured exposure; (3) studies with MS as an outcome of interest and (4) studies that reported (or included information for calculation of) mean and standard deviation (SD) between MS patients and healthy controls. All retrieved articles were screened based on titles and abstract, using the following exclusion criteria: (1) irrelevant and non-original papers; (2) in vitro, cell line, and animal studies; (3) case reports and case series reports and (4) studies without a control group.

\subsection{Data extraction and quality assessment}

The following information was extracted from each eligible study: the mean and SD of copper concentration, first authors' name, publication year, sample size, sex, study design, country, copper measurement methods, and specimen type. We used the Newcastle-Ottawa (NOS) checklist to assess the quality of included studies. The NOS is a risk of bias assessment tools designed for nonrandomized studies (Wells et al., 2000). A maximum of eight stars was awarded to each study related to the following three sections: four for selection, two for comparability, and two for exposure. The range of possible scores was 0 to 8 .

\subsection{Statistical analysis}

We selected standardized mean difference (SMD) as a measure of association to address the potential variability in copper measurement between assays. In meta-analysis studies, the SMD is commonly used as a measure of association when the included studies all assess the same outcome, but the exposure of interest measured in a variety of ways. We computed the SMD and corresponding 95\% confidence intervals (CI) using the Cohen method:

$\mathrm{SMD}=\frac{\text { mean of copper in MS patients }- \text { mean of copper in healthy control }}{\text { pooled standard deviation }}$

Combined SMDs were calculated using fixed-effect model as the main method and random effect model as a sensitivity analysis. We selected the fixed-effect model as the main approach because it assigns more weight to the studies with larger sample size and provides better statistical power, in particular, when dealing with individual studies with small sample size. Heterogeneity was calculated using the $I^{2}$ index, Cochran's $\mathrm{Q}$ test and $\tau^{2}$ statistics. All statistical analyses were conducted separately for each specimen type. Publication bias (small study effect) was examined using Egger's test and visualization of funnel plots. Statistical analyses were performed using R, version 3.3 (R Foundation for Statistical Computing, Vienna, Austria).

\section{Results}

\subsection{Selection and characteristics of included studies}

The flow diagram of the search strategy is shown in Fig. 1. First, we retrieved 955 records from which we excluded 213 duplicates. Titles and abstracts of 742 records were then screened from which 86 were selected for full-text assessment. After review of full texts, 23 studies (Alimonti et al., 2007; De Riccardis et al., 2018; Forte et al., 2005; Gellein et al., 2008; Ghazavi et al., 2012; Ghoreishi et al., 2015; Giacoppo et al., 2014; Harbige et al., 2011; Iranmanesh et al., 2012; Janghorbani et al., 2017; Kapaki et al., 1989; Masoud and Fakharian, 2007; Melø et al., 2003; Moradi et al., 2016; Palm and Hallmans, 1982; Plum and Hansen, 1960; Rieder et al., 1983; Ristori et al., 2011; Sedighi et al., 2013b; Smith et al., 1989; Socha et al., 2017; Ward and Minski, 1982; Wikström et al., 1976) were eligible for inclusion, from which four were excluded because of insufficient information (Alimonti et al., 2007; Moradi et al., 2016; Sedighi et al., 2013b; Ward and Minski, 1982). Also, we found a new eligible study after updating the search strategy and thus included in the final analysis (Siotto et al., 2019). Finally, twenty studies (all case-control study) consisting of 797 MS cases and 875 healthy controls were included in this meta-analysis. Detailed characteristics of the included studies are presented in Table 1. Four studies were included in the meta-analysis of concentration of copper in plasma (Gellein et al., 2008; Harbige et al., 2011; Janghorbani et al., 2017; Smith et al., 1989), four studies for whole blood analysis (Gellein et al., 2008; Harbige et al., 2011; Janghorbani et al., 2017; Smith et al., 1989), twelve studies for analysis based on serum concentration (De Riccardis et al., 2018; Ghazavi et al., 2012; Ghoreishi et al., 2015; Iranmanesh et al., 2012; Kapaki et al., 1989; Masoud and Fakharian, 2007; Palm and Hallmans, 1982; Plum and Hansen, 1960; Ristori et al., 2011; Siotto et al., 2019; Socha et al., 2017; Wikström et al., 1976); and four studies for analysis based on copper concentration in cerebrospinal fluid (De Riccardis et al., 2018; Gellein et al., 2008; Kapaki et al., 1989; Melø et al., 2003). The median score for the quality assessment was seven stars. The details of the quality assessment score were reported in Supplementary Table S1.

\subsection{Main findings}

There was observable evidence of a higher concentration of copper in MS patients. Fig. 2 shows the forest plot of combined estimates for the association between copper concentration in plasma. We found 

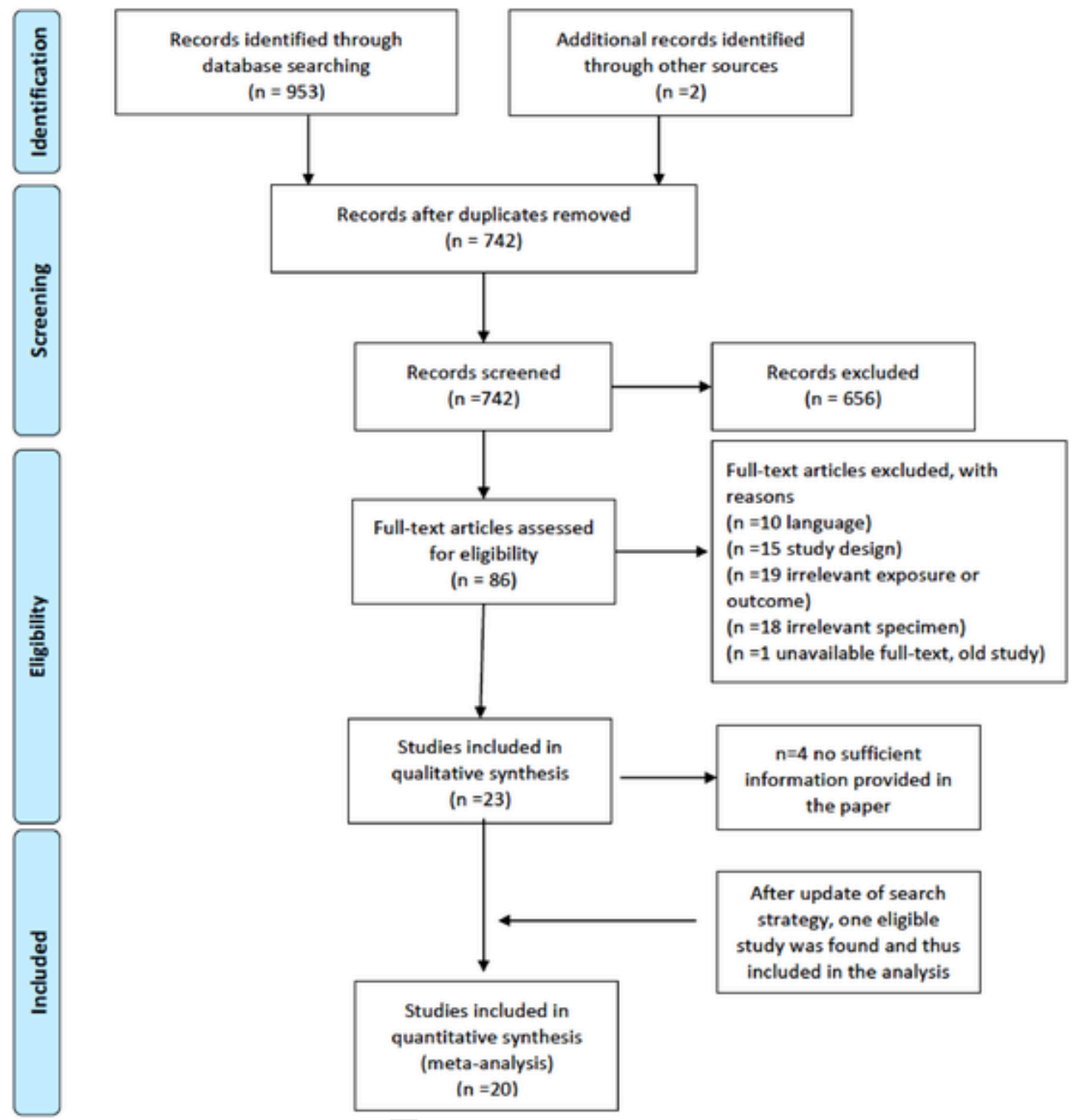

Fig. 1. Flow diagram of the search strategy.

a significantly higher level of copper concentration in plasma of MS patients than the control group (SMD 1.25, CI 95\% 0.95 to 1.55). In line with this finding, a higher level of copper concentration was observed in MS patients based on whole blood measurement (SMD: 0.45, CI $95 \% 0.22$ to 0.68 ) (Fig. 3). Also, we found a mild increase in the concentration of copper on the blood serum of MS patients (SMD 0.19, CI $95 \% 0.06$ to 0.33 ) (Fig. 4). Based on the results obtained through cerebrospinal fluid measurement, the level of copper concentration was observably higher in MS patients than control groups (SMD 1.23, 95\% CI 1.23 to 1.64 ) (Fig. 5). However, there was significant heterogeneity for all analyses. We did not found any observable evidence for publication bias based on the funnel plot and linear regression test of funnel plot asymmetry $(P$-value $=0.68)$ (Supplementary Fig. S1). In the sensitivity analysis using the random-effect model as a more conservative approach, the findings were broadly similar to the fixed-effet model. However, the CIs in the random-effect model was less precise, which is because of observable heterogeneity between included studies.

\section{Discussion}

\subsection{Important findings}

In this meta-analysis, we combined all available evidence to assess the association between copper concentration and MS disease. We found a higher concentration of copper in MS patients than in healthy controls. The magnitude of association was higher in studies that measured copper concentration in the plasma and cerebrospinal fluid. The consistency of the findings in different tissues, together with the strength of the association, underpin the possible role of copper in the etiology of MS. These findings could trigger future studies with larger sample sizes and longitudinal designs.

To our knowledge, no meta-analysis study has yet assessed the role of copper in MS disease. However, the previous studies reported a higher concentration of copper in other chronic diseases and neurological disorders such as Alzheimer's disease (Wang et al., 2015), depressive disorder ( $\mathrm{Ni}$ et al., 2018), and diabetes mellitus (Qiu et al., 2017). Our findings are supported by pathophysiological studies that have revealed that the accumulation of metals could lead to neurode- 
Table 1

Description and characteristics of studies included in the meta-analysis.

\begin{tabular}{|c|c|c|c|c|c|c|c|c|c|}
\hline Study & Sex & Country & $\begin{array}{l}\text { Multiple } \\
\text { sclerosis }\end{array}$ & $\begin{array}{l}\text { Healthy } \\
\text { control }\end{array}$ & $\begin{array}{l}\text { Copper level }(\mu \mathrm{g} / \mathrm{l}) \text { in } \\
\text { Multiple Sclerosis cases }\end{array}$ & $\begin{array}{l}\text { Copper level }(\mu \mathrm{g} / \mathrm{l}) \text { in } \\
\text { healthy controls }\end{array}$ & $\begin{array}{l}\text { Copper } \\
\text { measurement } \\
\text { methods }\end{array}$ & $\begin{array}{l}\text { Specimen } \\
\text { type }\end{array}$ & Qualityscore \\
\hline & & & $\mathrm{N}$ & $\mathrm{N}$ & Mean (SD) & Mean (SD) & & & \\
\hline Ghoreishi A & $\mathrm{T}$ & Iran & 50 & 50 & $1882(82.4)$ & $1031(44.5)$ & Polarography & Serum & 5 \\
\hline Siotto M & $\mathrm{T}$ & Italy & 60 & 40 & $873.12(18.43)$ & $815.93(20.97)$ & Colorimetric & Serum & 8 \\
\hline Ristori G & $\mathrm{T}$ & Italy & 49 & 49 & $916(160)$ & 956 (193) & MS or OS & Serum & 7 \\
\hline Plum CM & $\mathrm{T}$ & US & 78 & 94 & 1240.9 (185.9) & $1168.1(164)$ & N/A & Serum & 3 \\
\hline Wikström J & $\mathrm{T}$ & Finland & 6 & 10 & $1500(380)$ & 1740 (139) & AAS & Serum & 5 \\
\hline Kapaki E & $\mathrm{T}$ & Greece & 15 & 28 & $870(150)$ & $1030(140)$ & AAS & Serum & 6 \\
\hline $\begin{array}{l}\text { Iranmanesh } \\
\text { M }\end{array}$ & $\mathrm{T}$ & Iran & 25 & 25 & 885.8 (195.5) & 1103.7 (371.0) & $\begin{array}{l}\text { Colorimetric auto- } \\
\text { analyzer }\end{array}$ & Serum & 6 \\
\hline Palm R & M & Sweden & 21 & 35 & $936(235.7)$ & $974.52(101.91)$ & FAAS & Serum & 7 \\
\hline Palm R & $\mathrm{F}$ & Sweden & 29 & 35 & $1000(210.2)$ & $1070.06(133.75)$ & FAAS & Serum & 7 \\
\hline Socha K & M & Poland & 37 & 21 & 745 (217) & $1071(362)$ & ES & Serum & 8 \\
\hline Socha K & $\mathrm{F}$ & Poland & 64 & 47 & $1034(440)$ & $1007(416)$ & ES & Serum & 8 \\
\hline Masoud SA & M & Iran & 7 & 7 & $1062(204)$ & $1221(57)$ & ELISA & Serum & 7 \\
\hline Masoud SA & $\mathrm{F}$ & Iran & 28 & 28 & 1117 (189) & 1367 (131) & ELISA & Serum & 7 \\
\hline Ghazavi A & M & Iran & 17 & 22 & 1113.5 (391.9) & 856.1 (319) & Colorimetric & Serum & 7 \\
\hline Ghazavi A & $\mathrm{F}$ & Iran & 43 & 38 & $1151.8(412)$ & $939(296)$ & Colorimetric & Serum & 7 \\
\hline $\begin{array}{l}\text { De Riccardis } \\
\mathrm{L}\end{array}$ & $\mathrm{T}$ & Italy & 38 & 39 & $1044.69(45.12)$ & 819.74 (69.27) & AAS & Serum & 8 \\
\hline $\begin{array}{l}\text { Janghorbani } \\
\text { M }\end{array}$ & $\mathrm{T}$ & Iran & 55 & 95 & $1670.0(223.3)$ & $1060.0(194.9)$ & ICP-AES & Plasma & 7 \\
\hline Harbige L & $\mathrm{T}$ & UK & 21 & 9 & 1119 (309) & 957 (189) & ICP-MS & Plasma & 4 \\
\hline Gellein K & $\mathrm{T}$ & Norway & 9 & 13 & 487 (117) & $478(133.4)$ & HR-ICP-MS & Plasma & 8 \\
\hline Smith DK & $\mathrm{T}$ & US & 27 & 33 & $1684(462.3)$ & $1684(255.6)$ & AAS & Plasma & 7 \\
\hline Gellein K & $\mathrm{T}$ & Norway & 9 & 13 & $944(252)$ & $859(108.1)$ & HR-ICP-MS & Blood & 8 \\
\hline Rieder $\mathrm{H}$ & M & Switzerland & 53 & 14 & $856.96(166.4)$ & 859.04 (114.4) & AAS & Blood & 7 \\
\hline Rieder H & $\mathrm{F}$ & Switzerland & 63 & 21 & $888.16(187.2)$ & 968.24 (197.6) & AAS & Blood & 7 \\
\hline Forte $\mathrm{G}$ & $\mathrm{T}$ & Italy & 60 & 60 & $1445(481)$ & $926(144)$ & ICP-AES & Blood & 7 \\
\hline Giacoppo S & $\mathrm{T}$ & Italy & 41 & 23 & $628.9(177.0)$ & 609.7 (198.5) & ICP-MS & Blood & 7 \\
\hline Gellein K & $\mathrm{T}$ & Norway & 9 & 13 & $21.6(6.9)$ & $21.7(7.2)$ & HR-ICP-MS & CSF & 8 \\
\hline Melø TM & $\mathrm{T}$ & Norway & 18 & 18 & 10.909 (4.7) & $8.67(2.0)$ & ICP-MS & $\mathrm{CSF}$ & 6 \\
\hline Kapaki E & $\mathrm{T}$ & Greece & 15 & 28 & $31.6(18.72)$ & $40.20(14.26)$ & AAS & CSF & 6 \\
\hline $\begin{array}{l}\text { De Riccardis } \\
\mathrm{L}\end{array}$ & $\mathrm{T}$ & Italy & 38 & 39 & $10.87(1.27)$ & $5.59(0.64)$ & AAS & CSF & 8 \\
\hline
\end{tabular}

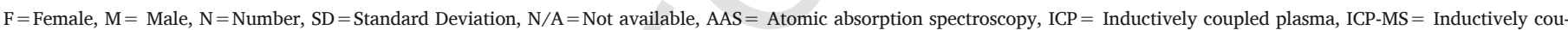

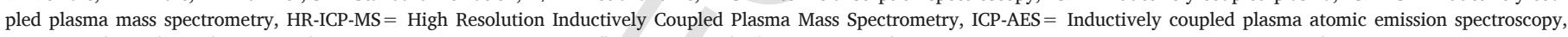

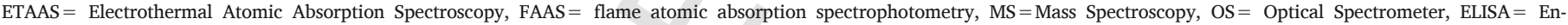
zyme-Linked Immunosorbent Assay

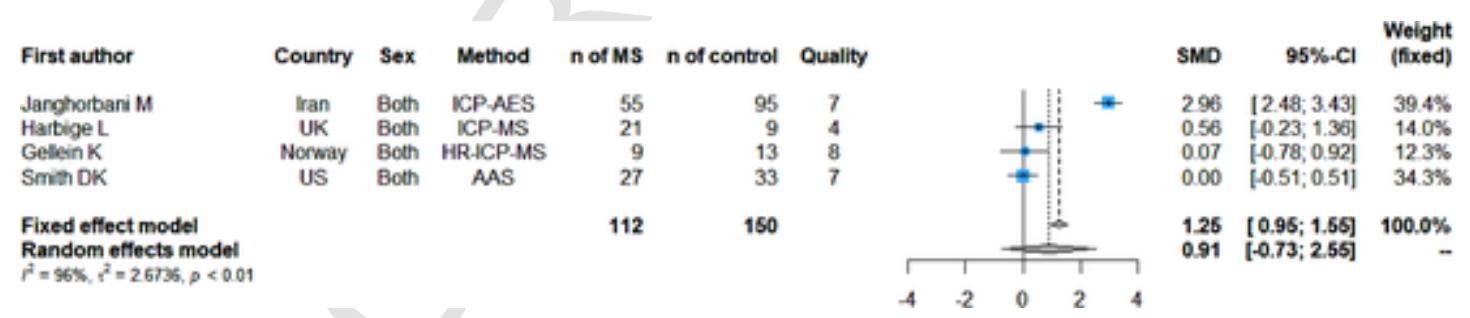

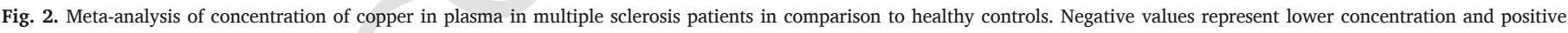

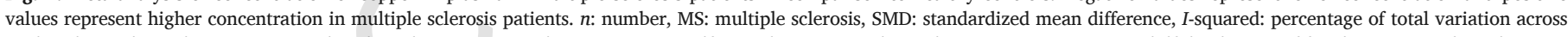

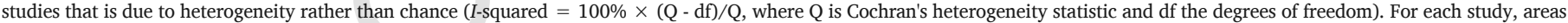
of square are proportional to weight (sample size), horizontal line indicate $95 \%$ confidence interval, and diamonds indicate pooled effect measures.

generation through oxidative stress, mitochondrial dysfunction, and death of cells (Mezzaroba et al., 2019).

\subsection{Biological mechanism}

Copper is a crucial trace metal that regulates the function of enzymes responsible for neurotransmitter synthesis, oxygen and electron transport, and protein modification (Kawamata and Manfredi, 2010; Mezzaroba et al., 2019). Nevertheless, excess amounts of copper gen- erate free radicals through the conversion of mitochondrial oxidative respiration products to toxic hydroxyl free radicals (Mezzaroba et al., 2019). Indeed, increased reactive oxygen species production in CNS is attributed to the redox properties of $\mathrm{Cu}$ ions (Heales et al., 1999; Rana et al., 2018). The previous evidence showed that the high concentration of $\mathrm{Cu}$ is neurotoxic and play a pathogenic role in neurodegenerative diseases such as Parkinson's disease and MS (Mezzaroba et al., 2019). Another explanation is that excess amount of $\mathrm{Cu}$ reduces $\mathrm{Zn}$ absorption, and this process leads to the gradual deple- 


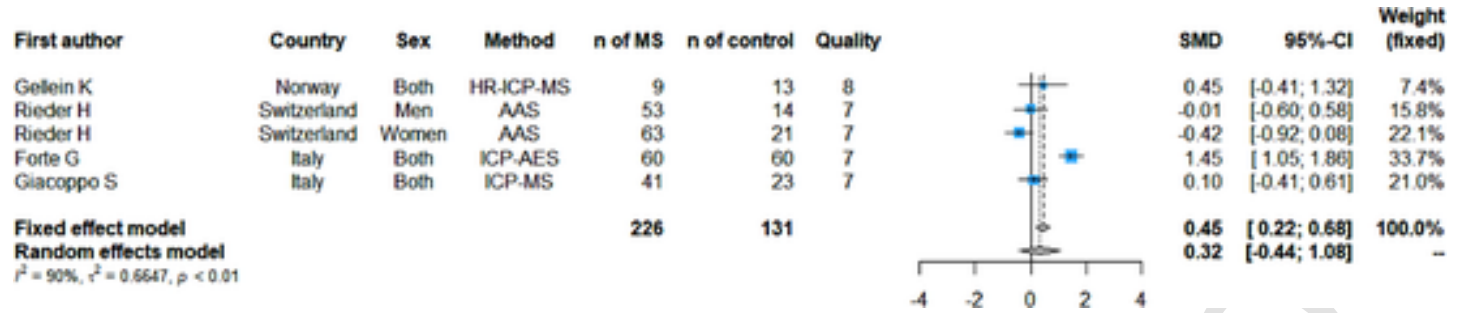

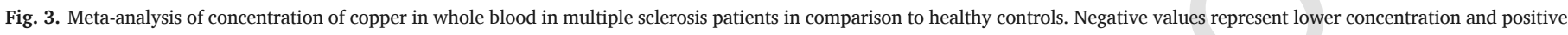

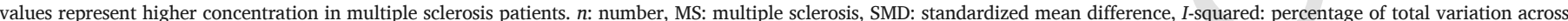

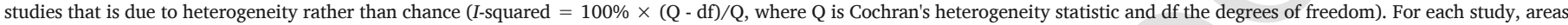
of square are proportional to weight (sample size), horizontal line indicate $95 \%$ confidence interval, and diamonds indicate pooled effect measures.

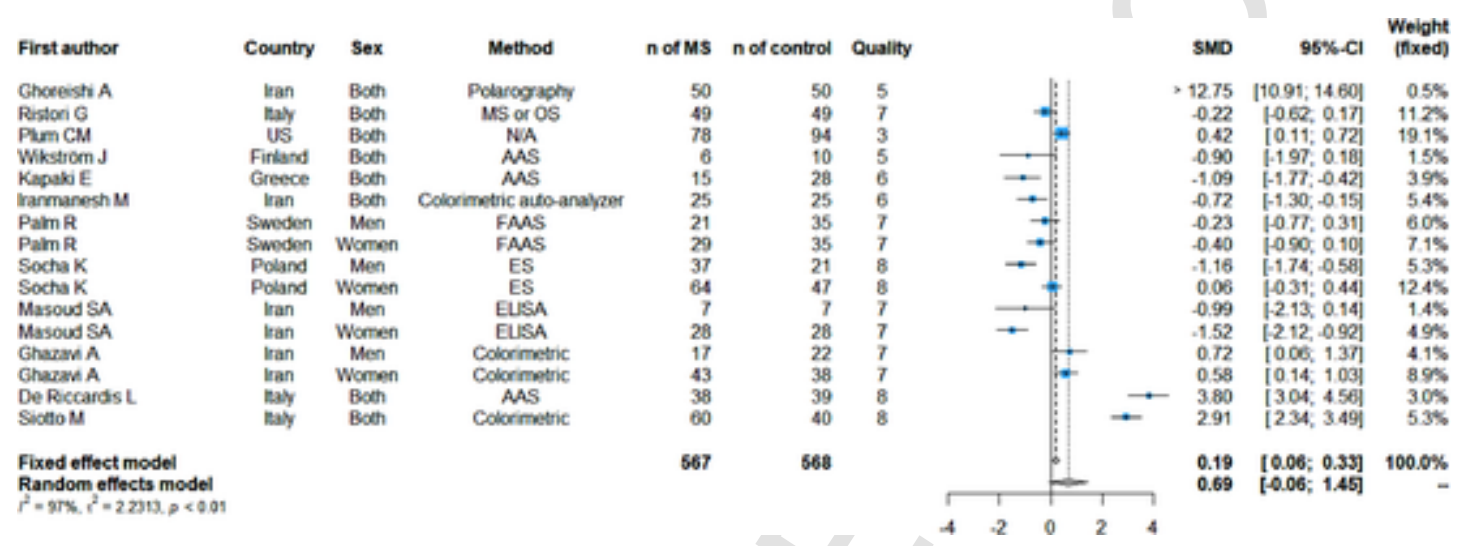

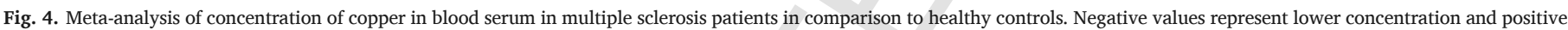

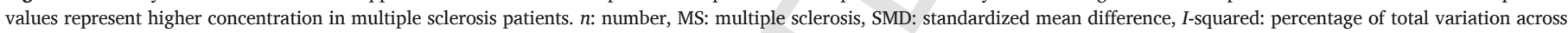

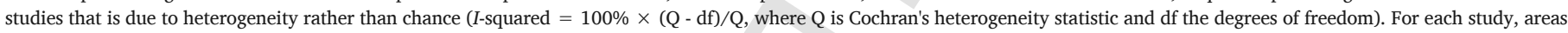
of square are proportional to weight (sample size), horizontal line indicate $95 \%$ confidence interval, and diamonds indicate pooled effect measures.

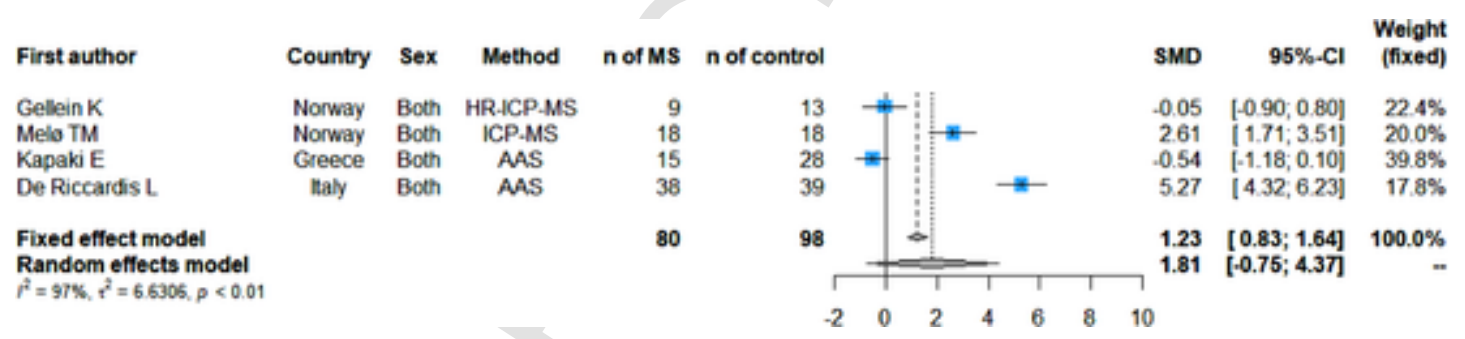

Fig. 5. Meta-analysis of concentration of copper in cerebrospinal fluid in multiple sclerosis patients in comparison to healthy controls.

tion of $\mathrm{Zn}$ that is an essential part of zinc fingers of the protein TPO-1 that is involved in the myelin synthesis in the oligodendrocytes (Johnson, 2000). Furthermore, a high $\mathrm{Cu} / \mathrm{Zn}$ ratio as a proxy of impaired $\mathrm{Zn}$ and $\mathrm{Cu}$ homeostasis has been reported in elderly patients with neurodegenerative diseases (Malavolta et al., 2015).

\subsection{Strength and limitation}

This study has some limitations worth mentioning. First, this meta-analysis was based on observational evidence; therefore, we cannot confirm the causality of the observed association. However, in the absence of large-scale prospective cohort studies, this meta-analysis provides the best level of evidence for this association so far. Second, we can not evaluate the possible effect of reverse causation in this study. Previous studies demonstrated that biochemical changes induced by MS disease could alter the level of specific elements, such as copper, in the cerebrospinal fluid (Smith et al., 1989). Without prospective cohort data, we are not able to assess the possible effect of reverse causation as one of the possible justification for this finding. Finally, the level of heterogeneity was significantly high in all the separated analyses.
This high heterogeneity level could be driven by the different laboratory method, which was used for the measurement of copper in each study.

\subsection{Conclusion}

We found a higher concentration of copper in multiple sclerosis patients than in healthy controls. Large-scale cohort or nested case-control studies are needed to investigate the temporality of the association to untangle the mechanism of the observed association.

\section{Funding}

The authors declare that there is no conflict of interest. This work was supported by the Torbat Heydariyeh University of Medical Sciences, Iran [grant number: REC.THUMS.IR.1396.22]. Nazarzadeh is supported by the British Heart Foundation (fellowship grant; ref. 34346). The funders had no role in study design, data collection and analysis, decision to publish, or preparation of the manuscript.

\section{CRediT authorship contribution statement}

Mohammad Sarmadi: Funding acquisition, Project administration, Visualization, Writing - review \& editing, Writing - origi- 
nal draft, Resources, Investigation, Methodology, Conceptualization. Zeinab Bidel: Writing - review \& editing, Writing - original draft, Investigation, Formal analysis, Software, Methodology. Fereshteh Najafi: Writing - review \& editing, Investigation. Rema Remakrishnan: Writing - review \& editing, Writing - original draft, Investigation, Methodology. Farshad Teymoori: Writing - review \& editing, Writing - original draft, Investigation. Hassan Azhdari Zarmehri: Writing - review \& editing, Investigation. Milad Nazarzadeh: Funding acquisition, Project administration, Supervision, Visualization, Writing review \& editing, Writing - original draft, Resources, Investigation, Formal analysis, Validation, Software, Methodology, Conceptualization.

\section{Declaration of Competing Interest}

The authors declare that there is no conflict of interest

\section{Acknowledgments}

This work was supported by the Torbat Heydariyeh University of Medical Sciences, Iran [grant number: REC.THUMS.IR.1396.22]. Nazarzadeh is supported by the British Heart Foundation (fellowship grant; ref. 34346).

\section{Supplementary materials}

Supplementary material associated with this article can be found, in the online version, at doi:10.1016/j.msard.2020.102426.

\section{References}

Alimonti, A, Ristori, G, Giubilei, F, Stazi, M A, Pino, A, Visconti, A, Brescianini, S, Monti, M S, Forte, G, Stanzione, P, Bocca, B, Bomboi, G, D'Ippolito, C, Annibali, V, Salvetti, M, Sancesario, G, 2007. Serum chemical elements and oxidative status in Alzheimer's disease, Parkinson disease and multiple sclerosis. Neurotoxicology 28, 450-456. https: //doi.org/10.1016/j.neuro.2006.12.001

Ascherio, A, Munger, K L, Lennette, E T, Spiegelman, D, Hernán, M A, Olek, M J, Hankinson, S E, Hunter, D J, 2001. Epstein-Barr virus antibodies and risk of multiple sclerosisa prospective study. JAMA 286, 3083-3088. https://doi.org/10.1001/jama. 286.24.3083.

Ascherio, A, Munger, K L, Simon, K C, 2010. Vitamin D and multiple sclerosis. Lancet Neurol. 9, 599-612. https://doi.org/10.1016/S1474-4422(10)70086-7.

Bredholt, M, Frederiksen, J L, 2016. Zinc in multiple sclerosis. ASN Neuro 8 175909141665151. https://doi.org/10.1177/1759091416651511.

De Riccardis, L, Buccolieri, A, Muci, M, Pitotti, E, De Robertis, F, Trianni, G, Manno, D, Maffia, M, 2018. Copper and ceruloplasmin dyshomeostasis in serum and cerebrospinal fluid of multiple sclerosis subjects. Biochimica et Biophysica Acta (BBA) - Molecular Basis of Disease 1864, 1828-1838. https://doi.org/10.1016/j.bbadis. 2018.03.007.

Eliaeson, K., Liljeberg, M., Bjork, A., Kockum, I., Skelton, A., Lindstrom, E.J., 2008. Relationships of geochemistry and multiple sclerosis.

Forte, G, Visconti, A, Santucci, S, Ghazaryan, A, Figà-Talamanca, L, Cannoni, S, Bocca, B, Pino, A, Violante, N, Alimonti, A, Salvetti, M, Ristori, G, 2005. Quantification of chemical elements in blood of patients affected by multiple sclerosis. Annali dell'Istituto Superiore di Sanita 41, 213-216.

Gellein, K, Skogholt, J H, Aaseth, J, Thoresen, G B, Lierhagen, S, Steinnes, E, Syversen, T, Flaten, T P, 2008. Trace elements in cerebrospinal fluid and blood from patients with a rare progressive central and peripheral demyelinating disease. J. Neurol. Sci. 266, 70-78. https://doi.org/10.1016/j.jns.2007.08.042.

Ghazavi, A, Kianbakht, S, Ghasami, K, Mosayebi, G, 2012. High copper and low zinc serum levels in iranian patients with multiple sclerosis: a case control study. Clin. Lab. 58, 161-164.

Ghoreishi, A, Mohseni, M, Amraei, R, Alizadeh, A M, Mazloomzadeh, S, 2015. Investigation the amount of copper, lead, zinc and cadmium levels in serum of Iranian multiple sclerosis patients. J. Chem. Pharm. Sci. 8, 40-45.

Giacoppo, S, Galuppo, M, Calabrò, R S, D’Aleo, G, Marra, A, Sessa, E, Bua, D G, Potortì, A G, Dugo, G, Bramanti, P, Mazzon, E, 2014. Heavy metals and neurodegenerative diseases: an observational study. Biol. Trace Elem. Res. 161, 151-160. https://doi. org/10.1007/s12011-014-0094-5.

Gupta, A, Lutsenko, S, 2009. Human copper transporters: mechanism, role in human diseases and therapeutic potential. Future Med. Chem. 1, 1125-1142. https://doi.org/ 10.4155/fmc.09.84.

Handel, A E, Williamson, A J, Disanto, G, Dobson, R, Giovannoni, G, Ramagopalan, S V, 2011. Smoking and multiple sclerosis: an updated meta-analysis. PLoS One 6, e16149. https://doi.org/10.1371/journal.pone.0016149.

Harbige, L S, Pinto, E, Xiang, M, Shareif, M K, 2011. Circulating plasma cytokines, zinc, copper, vitamins $\mathrm{A}$ and $\mathrm{E}$ in multiple sclerosis patients and healthy controls. Proc. Nutr. Soc. 70 E36-E36. https://doi.org/10.1017/s002966511100067x.
Hay, S I, Abajobir, A A, Abate, K H, Abbafati, C, Abbas, K M, et al., 2016. Global, regional, and national disability-adjusted life-years (DALYs) for 333 diseases and injuries and healthy life expectancy (HALE) for 195 countries and territories, 1990-2016: a systematic analysis for the Global Burden of Disease Study. Lancet North Am. Ed. 390, 1260-1344. https://doi.org/10.1016/S0140-6736(17)32130-X.

Heales, S J R, Bolaños, J P, Stewart, V C, Brookes, P S, Land, J M, Clark, J B, 1999. Nitric oxide, mitochondria and neurological disease. Biochimica et Biophysica Acta Bioenergetics 1410, 215-228. https://doi.org/10.1016/S0005-2728(98)00168-6.

Houtchens, M K, Edwards, N C, Schneider, G, Stern, K, Phillips, A L, 2018. Pregnancy rates and outcomes in women with and without MS in the United States. Neurology 91, e1559-e1569. https://doi.org/10.1212/WNL.0000000000006384.

Iranmanesh, M, Iranmanesh, F, Sadeghi, H, 2012. Serum level of iron, zinc and copper in patients with multiple sclerosis. Pars Jahrom Univ. Med. Sci. 10, 1-5. https://doi.org/ 10.29252/jmj.10.4.1.

Janghorbani, M, Shaygannejad, V, Hakimdavood, M, Salari, M, 2017. Trace elements in serum samples of patients with multiple sclerosis. Athens J. Health 4, 145-154. https: //doi.org/10.30958/ajh.4-2-3.

Johnson, S, 2000. The possible role of gradual accumulation of copper, cadmium, lead and iron and gradual depletion of zinc, magnesium, selenium, vitamins B2, B6, D, and E essential fatty acids in multiple sclerosis. Med. Hypotheses 55, 239-241. https://doi. org/10.1054/mehy.2000.1051.

Kapaki, E, Segditsa, J, Papageorgiou, C, 1989. Zinc, copper and magnesium concentration in serum and CSF of patients with neurological disorders. Acta Neurol. Scand. 79, 373-378. https://doi.org/10.1111/j.1600-0404.1989.tb03803.x.

Kawamata, H, Manfredi, G, 2010. Import, maturation, and function of SOD1 and its copper chaperone CCS in the mitochondrial intermembrane space. Antioxid. Redox Signal.. https://doi.org/10.1089/ars.2010.3212.

Malavolta, M, Piacenza, F, Basso, A, Giacconi, R, Costarelli, L, Mocchegiani, E, 2015. Serum copper to zinc ratio: relationship with aging and health status. Mech. Ageing Dev.. https://doi.org/10.1016/j.mad.2015.01.004.

Masoud, S A, Fakharian, E, 2007. Assessment of serum magnesium, copper, and zinc levels in multiple sclerosis (MS) patients. Iran. J. Psychiatry Behav. Sci. 1, 38-42.

Melø, T M, Larsen, C, White, L R, Aasly, J, Sjøbakk, T E, Flaten, T P, Sonnewald, U, Syversen, T, 2003. Manganese, copper, and zinc in cerebrospinal fluid from patients with multiple sclerosis. Biol. Trace Elem. Res. 93, 1-8. https://doi.org/10.1385/BTER: 93:1-3:1.

Mezzaroba, L, Alfieri, D F, Colado Simão, A N, Vissoci Reiche, E M, 2019. The role of zinc, copper, manganese and iron in neurodegenerative diseases. Neurotoxicology 74, 230-241. https://doi.org/10.1016/j.neuro.2019.07.007.

Moher, D, Liberati, A, Tetzlaff, J, Altman, D G, Group, P R I S M A, 2009. Preferred reporting items for systematic reviews and meta-analyses: the PRISMA statement. PLoS Med. 6, e1000097. https://doi.org/10.1371/journal.pmed.1000097.

Moradi, A, Honarjoo, N, Etemadifar, M, Fallahzade, J, 2016. Bio-accumulation of some heavy metals in blood serum of residents in Isfahan and Shiraz, Iran. Environ. Monit. Assess. 188, 269. https://doi.org/10.1007/s10661-016-5217-3.

Morandi, E, Jagessar, S A, 't Hart, B A, Gran, B, 2017. EBV infection empowers human B cells for autoimmunity: role of autophagy and relevance to multiple sclerosis. J. Immunol. 199, 435-448. https://doi.org/10.4049/jimmunol.1700178.

Ni, M, You, Y, Chen, J, Zhang, L, 2018. Copper in depressive disorder: a systematic review and meta-analysis of observational studies. Psychiatry Res. 267, 506-515. https://doi. org/10.1016/j.psychres.2018.05.049.

Olsson, T, Barcellos, L F, Alfredsson, L, 2016. Interactions between genetic, lifestyle and environmental risk factors for multiple sclerosis. Nat. Rev. Neurol.. https://doi.org/ 10.1038/nrneurol.2016.187.

Palm, R, Hallmans, G, 1982. Zinc and copper in multiple sclerosis. J. Neurol. Neurosurg. Psychiatry 45, 691-698. https://doi.org/10.1136/jnnp.45.8.691.

Plum, C M, Hansen, S E, 1960. Studies on variations in serum copper and serum copper oxidase activity, together with studies on the copper content of the cerebrospinal fluid, with particular reference to the variations in multiple sclerosis. Acta Psychiatr. Scand. 35, 41-78. https://doi.org/10.1111/j.1600-0447.1960.tb08680.x.

Qiu, Q, Zhang, F, Zhu, W, Wu, J, Liang, M, 2017. Copper in diabetes mellitus: a meta-analysis and systematic review of plasma and serum studies. Biol. Trace Elem. Res. 177, 53-63. https://doi.org/10.1007/s12011-016-0877-y.

Rana, S, Prasoon, A, Sadhukhan, P, Jha, P K, Sathe, V, Barman, S R, Ballav, N, 2018. Spontaneous reduction of copper(II) to copper(I) at solid-liquid interface. J. Phys. Chem. Lett. 9, 6364-6371. https://doi.org/10.1021/acs.jpclett.8b02844.

Rieder, H P, Schoettli, G, Seiler, H, 1983. Trace elements in whole blood of multiple sclerosis. Eur. Neurol. 22, 85-92. https://doi.org/10.1159/000115542.

Riise, T, Nortvedt, M W, Ascherio, A, 2003. Smoking is a risk factor for multiple sclerosis. Neurology 61, 1122-1124. https://doi.org/10.1212/01.WNL.0000081305.66687.D2.

Ristori, G, Brescianini, S, Pino, A, Visconti, A, Vittori, D, Coarelli, G, Cotichini, R, Bocca, B, Forte, G, Pozzilli, C, Pestalozza, I, Stazi, M A, Alimonti, A, Salvetti, M, 2011. Serum elements and oxidative status in clinically isolated syndromes: Imbalance and predictivity. Neurology 76, 549-555. https://doi.org/10.1212/WNL. 0b013e31820af7de.

Sedighi, B, Ebrahimi, H A, Haghdoost, A A, Abotorabi, M, 2013. Comparison of serum levels of copper and zinc among multiple sclerosis patients and control group. Iran. J. Neurol. 12, 125-128.

Sedighi, B, Ebrahimi, H A, Haghdoost, A A, Abotorabi, M, 2013. Comparison of serum levels of copper and zinc among multiple sclerosis patients and control group. Iran. J. Neurol. 12, 125-128.

Siotto, M, Filippi, M M, Simonelli, I, Landi, D, Ghazaryan, A, Vollaro, S, Ventriglia, M, Pasqualetti, P, Rongioletti, M C A, Squitti, R, Vernieri, F, 2019. Oxidative stress related to iron metabolism in relapsing remitting multiple sclerosis patients with low disability. Front. Neurosci. 13, 86. https://doi.org/10.3389/fnins.2019.00086.

Smith, D K, Feldman, E B, Feldman, D S, 1989. Trace element status in multiple sclerosis. Am. J. Clin. Nutr. 50, 136-140. https://doi.org/10.1093/ajcn/50.1.136.

Socha, K, Karpińska, E, Kochanowicz, J, Soroczyńska, J, Jakoniuk, M, Wilkiel, M, Mariak, Z D, Borawska, M H, 2017. Dietary habits; concentration of copper, zinc, and Cu-to- 
$\mathrm{Zn}$ ratio in serum and ability status of patients with relapsing-remitting multiple sclerosis. Nutrition 39-40, 76-81. https://doi.org/10.1016/J.NUT.2017.03.009.

Tapiero, H, Tew, K D, 2003. Trace elements in human physiology and pathology: zinc and metallothioneins. Biomed. Pharmacother. 57, 399-411. https://doi.org/10.1016/ S0753-3322(03)00081-7.

Toschi, N, De Santis, S, Granberg, T, Ouellette, R, Treaba, C A, Herranz, E, Mainero, C, 2019. Evidence for progressive microstructural damage in early multiple sclerosis by multi-shell diffusion magnetic resonance imaging. Neuroscience 403, 27-34. https:// doi.org/10.1016/j.neuroscience.2019.01.022.

Usman, M S, El Zowalaty, M E, Shameli, K, Zainuddin, N, Salama, M, Ibrahim, N A, 2013. Synthesis, characterization, and antimicrobial properties of copper nanoparticles. Int. J. Nanomed. 8, 4467-4479. https://doi.org/10.2147/IJN.S50837.

van den Hoogen, W J, Laman, J D, 't Hart, B A, 2017. Modulation of multiple sclerosis and its animal model experimental autoimmune encephalomyelitis by food and gut microbiota. Front. Immunol. 8, 1081. https://doi.org/10.3389/fimmu.2017.01081.

Wang, Z.X., Tan, L., Wang, H.F., M.a., J., Liu, J., Tan, M.S., Sun, J.H., Zhu, X.C., Jiang, T., Yu, J.T., 2015. Serum iron, zinc, and copper levels in patients with alzheimer's disease: a replication study and meta-analyses. J. Alzheimer's Dis.47, 565-581. https:// doi.org/10.3233/JAD-143108
Ward, N I, Minski, M J, 1982. Comparison of Trace Elements in Whole Blood and Scalp Hair of Multiple Sclerosis Patients and Normal Individuals., in: D., H.D. (Ed.), Trace Substances in Environmental Health: Proceedings of University of Missouri's Annual Conferenc., Universityof Missouri, Columbia, Mo, USA. pp. 252-260.

Wells, G., Shea, B., O'Connell, D., Peterson, J., 2000. The Newcastle-Ottawa Scale (NOS) for assessing the quality of nonrandomised studies in meta-analyses [WWW Document]. Ottawa, ON: Ottawa Hospital Research Institute. URLhttp://www.ohri.ca/ programs/clinical_epidemiology/oxford.asp (accessed 7.11.20).

Wikström, J, Westermarcik, T, Palo, J, 1976. Selenium, vitamin E and copper in multiple sclerosis. Acta Neurol. Scand. 54, 287-290. https://doi.org/10.1111/j.1600-0404. 1976.tb04806.x.

Zuluaga, M I, Otero-Romero, S, Rovira, A, Perez-Hoyos, S, Arrambide, G, Negrotto, L, Galán, I, Río, J, Comabella, M, Nos, C, Arévalo, M J, Vidal-Jordana, A, Castilló, J, Rodríguez, B, Midaglia, L, Mulero, P, Mitjana, R, Auger, C, Sastre-Garriga, J, Montalban, X, Tintoré, M, 2019. Menarche, pregnancies, and breastfeeding do not modify long-term prognosis in multiple sclerosis. Neurology 92, e1507-e1516. https: //doi.org/10.1212/WNL.0000000000007178. 